\title{
Avaliação da analgesia de opioide tópico em úlcera de perna de paciente falcêmico
}

\author{
Evaluation of the topical application of opioid analgesia for a leg ulcer of a sickle cell \\ disease patient
}

Alexandre F. Neves ${ }^{l}$

Amanda Martins ${ }^{2}$

Ana Maria M. Queiroz ${ }^{3}$

Eleonora D'Avila Thomét

Ana Paula A. Queiroz ${ }^{5}$

Clarisse L. C. Lobo ${ }^{6}$
A doença falciforme é caracterizada por apresentar várias alterações clínicas e fisiopatológicas nos pacientes que por ela são acometidos. Uma dessas alterações é presença de úlceras de perna dolorosas e de difícil cicatrização, sendo necessário o apoio de equipe multiprofissional no seu manejo e tratamento. Com o objetivo de reduzir a dor associada a úlcera de perna, o paciente falcêmico faz uso de opioides parenterais e enterais que normalmente estão associados a efeitos colaterais indesejados. Com o objetivo de reduzir o uso desses opioides sistêmicos, avaliamos um gel de morfina, de fácil manipulação e baixo custo, que foi utilizado antes e após o processo de troca de curativo das úlceras de perna dos pacientes falcêmicos atendidos em nossa instituição. Baseados na escala analógica da dor foi avaliado o efeito analgésico do gel em 28 pacientes. Todos apresentavam dor grau 7 ou 8 antes da aplicação do gel. Vinte e quatro pacientes $(85,7 \%)$ apresentaram total ausência de dor por um período de 24 horas, não sendo necessário o uso de analgésicos sistêmicos. Em três pacientes (10,7\%) a ausência de dor durou um periodo de 12 horas. Somente um paciente $(3,6 \%)$ não relatou analgesia apos o uso do gel. Os resultados demonstraram que o gel é altamente eficaz no controle da dor das úlceras de perna de pacientes falcêmicos. Rev. Bras. Hematol. Hemoter. 2010;32(2):123-125.

Palavras-chave: Doença da Hemoglobina SC; analgésicos; dor.

\section{Introdução}

A doença falciforme representa a enfermidade hereditária mais prevalente no mundo. A Organização Mundial da Saúde sinaliza, em algumas regiões do mundo, para o surgimento de um caso novo da doença para cada 700 nascidos vivos. ${ }^{1}$

A doença falciforme é caracterizada pela presença da hemoglobina geneticamente modificada, denominada hemoglobina S. Quando uma quantidade determinada de hemo- globina S polimeriza o resultado final, é o dano celular irreversível, o afoiçamento das hemácias e o aparecimento de sinais e sintomas da doença. Esse fenômeno sofre ainda a influência de moléculas de adesão celular da hemácia com o endotélio, que se encontram aumentadas na doença falciforme. . $^{2-6}$

O processo de falcização normalmente promove crises álgicas que interferem na rotina do paciente. ${ }^{7,8}$ Outro processo fisiopatológico que está relacionado ao aumento da dor é o

${ }_{2}^{I}$ Farmacêutico. Farmácia Hospitalar. Hemorio - Rio de Janeiro-RJ.

${ }_{3}^{2}$ Enfermeira. Supervisora do Setor de Curativos. Hemorio - Rio de Janeiro-RJ.

${ }^{3}$ Hematologista. Coordenadora do Grupo da Dor. Hemorio - Rio de Janeiro-RJ.

${ }_{5}^{4}$ Dermatologista. Médica do Setor de Curativos. Hemorio - Rio de Janeiro-RJ.

${ }^{5}$ Farmacêutica. Chefe do Serviço de Farmácia. Hemorio - Rio de Janeiro-RJ.

${ }^{6}$ Hematologista. Diretora Geral do Hemorio - Rio de Janeiro-RJ.

Instituto Estadual de Hematologia Arthur de Siqueira Cavalcanti - Hemorio - Rio de Janeiro-RJ.

Correspondência: Alexandre Ferreira Neves

Rua Frei Caneca, 8 - Centro

20211-030 - Rio de Janeiro-RJ - Brasil

E-mail: ambulatorio.farmacia@hemorio.rj.gov.br

Doi: 10.1590/S1516-84842010005000033 
surgimento das úlceras de perna, que afetam aproximadamente $20 \%$ dos pacientes adultos, sendo mais prevalente nos pacientes SS e Sß0-talassemia. ${ }^{9}$ Surgem na adolescência, com pico de incidência após os 20 anos de idade. As lesões ocorrem, de preferência, nos maléolos mediais e laterais, uni ou bilateralmente. Estão, na maioria das vezes, associadas a pequenos traumatismos; entretanto, podem ocorrer espontaneamente, normalmente em pele ressecada ou com pequenas fissuras, podendo assumir grandes proporções, com cicatrização prolongada e recorrência frequente. ${ }^{10}$

O tratamento da úlcera de perna inclui: utilização de câmara hiperbárica, bota de unna, enxertos de pele, zinco oral e medicamentos tópicos variados. A multiplicidade de opções reflete a ineficácia de todos esses métodos em prevenir a recorrência da lesão. Apesar de todas essas opções terapêuticas, o controle do leito da ferida, mantendo a área limpa e com tecido de granulação, continua sendo a pedra fundamental do tratamento. ${ }^{11-14}$

\section{Casuística e Método}

O presente trabalho representa um estudo de natureza qualitativa, realizado com pacientes com diagnóstico de doença falciforme, regularmente matriculados no Instituto Estadual de Hematologia Arthur de Siqueira Cavalcanti Hemorio, que realizam procedimentos de troca de curativos de úlceras de perna e que fazem uso de terapêutica analgésica sistêmica com opioides. Foram excluídos do estudo os pacientes com histórico de alergia a opioides, com menos de 18 anos de idade, pacientes grávidas ou amamentando.

Numa tentativa de melhorar a analgesia durante os curativos, que são realizados com uma periodicidade de até três vezes na semana, dependendo do estágio das úlceras, e visando uma estratégia de evitar o uso de opioides sistêmicos, pelos seus efeitos colaterais, este trabalho analisou o uso de opioide tópico em úlceras de perna de pacientes falcêmicos, que, segundo a literatura, ${ }^{15-17}$ não apresentam os efeitos colaterais dos opioides sistêmicos, ou apresentam com intensidade muito pequena, estando diretamente relacionados com o tamanho da úlcera, e apresentando boa analgesia, aparentemente por ação em receptores periféricos. ${ }^{18}$

Os relatos da literatura citam a utilização de bases, comercializadas através das marcas Intrasite ${ }^{\circledR} \mathrm{Gel}^{15,16} \mathrm{e}$ Instillagel ${ }^{\circledR},{ }^{17}$ na preparação do gel de morfina. Em função do elevado custo dessas bases e da pretensão de elaborarmos uma metodologia que atenda as nossas necessidades dentro das nossas possibilidades, resolvemos utilizar como base o gel de Carbopol, que é um hidrogel,de baixo custo, facilmente manipulável e apresenta boa estabilidade. ${ }^{19,20}$

Todos os pacientes registrados no presente estudo, que foi aprovado pelo Comitê de Ética e Pesquisa do Hemorio, deram seu consentimento livre e esclarecido, conforme estabelecido pela Declaração de Helsinki. O levantamento de dados para a seleção dos pacientes foi feita pela revisão de prontuários e Fichas de Admissão da Sala de Curativos. As características das lesões cutâneas a serem estudas foram: úlceras de perna falciformes dolorosas, em esquema terapêutico com opioides sistêmicos e/ou analgésicos, medindo entre 2 e 50 centímetros quadrados, cujos leitos não estejam recobertos por debris e/ou necrose em mais do que $50 \%$ da área.

O gel de morfina foi aplicado no leito ulcerado antes e após a manipulação deste, e coberto com gaze estéril e atadura de crepon. Foi realizada nova troca após 48 horas, sendo empregada a Escala Analógica da Dor (EAD) ${ }^{21}$ para avaliação da dor percebida pelo paciente antes do procedimento, meia hora, 12 horas e 24 horas após a aplicação do gel de morfina.

A avaliação dos efeitos clínicos secundários locais e sistêmicos foi feita através dos prontuários dos pacientes no período de estudo, com relação às intercorrências clínicas, e por meio da dispensação de opioides para os referidos pacientes.

O gel de sulfato de morfina tópico foi preparado através da mistura progressiva do conteúdo de uma ampola de sulfato de morfina $10 \mathrm{mg} / \mathrm{ml}$, de $1 \mathrm{ml}$, com 8 gramas $(0,12 \%)$ de gel de Carbopol previamente preparado. Após a homogeneização, o gel foi acondicionado em frascos estéreis, protegidos da ação direta da luz e guardados à temperatura ambiente. A estabilidade do gel foi medida por meio da análise da concentração de sulfato de morfina com uso de cromatografia líquida de alto desempenho (HPLC). ${ }^{17}$

\section{Resultados}

De um total de 74 pacientes atendidos regularmente pela sala de curativos, foram selecionados 28 pacientes, levando-se em consideração os fatores excludentes do estudo e o tamanho da úlcera do paciente, que deveria estar compreendida entre $2 \mathrm{~cm}^{2}$ e $50 \mathrm{~cm}^{2}$. Dos 28 pacientes, 16 eram do sexo masculino e 12 do sexo feminino. A idade média dos pacientes que foram submetidos ao estudo foi de 30 anos, e o tamanho médio das úlceras foi de $8 \mathrm{~cm}^{2}$. Todos os pacientes relataram dor grau 7 ou 8 antes da aplicação do gel. Em 24 pacientes $(85,7 \%)$ obtivemos total ausência de dor, grau 1 , em até trinta minutos após a aplicação do gel, mantendo-se neste estado por um período de 24 horas, não sendo necessário o uso de analgésicos sistêmicos. Em três pacientes (10,7\%), a ausência de dor, após a aplicação do gel, durou um período de 12 horas. Somente um paciente $(3,6 \%)$ não relatou analgesia após a aplicação do gel.

\section{Discussão}

O presente estudo descritivo da utilização do gel de sulfato de morfina a $0,12 \%$, tendo como base o hidrogel Carbopol, apresentou resultados semelhantes aos descritos na literatura ${ }^{11-17} \mathrm{em}$ termos de analgesia alcançada, porém com a grande vantagem do custo relacionado à base utilizada 
na preparação do gel ser de valor bem inferior às bases normalmente utilizadas.

De uma forma geral, o gel foi bem tolerado pelos pacientes, não sendo descritas reações locais ou sistêmicas que possam estar associadas, numa primeira avaliação, ao produto aplicado. O rendimento do gel foi considerado satisfatório, onde $100 \mathrm{~g} / \mathrm{mês}$ foram utilizados para o atendimento de todos os pacientes envolvidos no estudo. Conforme já descrito na literatura, ${ }^{17}$ o gel apresentou boa estabilidade, mantendo concentração de sulfato de morfina superior a $95 \%$ por mais de seis meses, à temperatura ambiente.

A Escala Analógica da Dor (EAD) ${ }^{21}$ utilizada na avaliação do grau de dor do paciente que recebeu o gel de opioide, já vem sendo utilizada pelo serviço de emergência de nossa instituição, fato este que facilitou o entendimento, por parte do paciente, do seu funcionamento, e o acompanhamento pelo médico durante a avaliação clínica do paciente. Nesse sentido, os resultados foram bastante satisfatórios, sendo uma ferramente que permitiu uma boa avaliação do grau de dor do paciente.

Outro fato observado no presente estudo foi a ação debridante do gel, que, por ser um hidrogel, evitou o ressecamento da lesão, facilitando seu manuseio durante a troca de curativos. Entretanto, outras questões permanecem sem respostas, e estudos randomizados, duplo-cego, com outros analgésicos de uso tópico poderão ser úteis na elucidação, assim como relacionar a duração do efeito analgésico e a ausência de reações adversas à concentração de morfina no gel. Nosso grupo encontra-se no momento conduzindo esses estudos na tentativa de elucidar essas questões.

\begin{abstract}
Sickle cell disease is characterized by several clinical and pathophysiological changes including painful leg ulcers. These are difficult to heal and require the support of a multidisciplinary team in their management. The treatment of pain in these patients usually involves the use of opioids. In order to reduce the use of systemic opioids, we evaluated an easy-to-use low-cost morphine gel (0.12\%) that was applied before and after changing leg ulcer dressings of sickle cell patients treated in Hemorio hospital. Based on the Analogue Pain Scale (APS) we evaluated the analgesic effect of the gel with 28 patients. All presented with a degree of pain of 7 or 8 before applying the gel. A total absence of pain was observed by 24 patients $(85.7 \%)$ within thirty minutes of applying the gel, with the analgesia effect being maintained for a period of 24 hours and thus the use of other analgesics was not requiring. In 3 patients (10.7\%) no pain was reported for a period of 12 hours. Only 1 patient (3.6\%) reported no analgesic effect thirty minutes after the application of the gel. Our results indicate that the morphine gel was effective in controlling the pain of leg ulcers in this group of sickle cell patients. A controlled study should be designed to assess this important subject. Rev. Bras. Hematol. Hemoter. 2010;32(2):123-125.
\end{abstract}

Key words: Hemoglobin SC disease; analgesics; pain.

\section{Referências Bibliográficas}

1. WHO. Advisory Group on Hereditary Disease. Geneve: WHO, 1985.

2. Schechter AN, Noguchi CT. Sickle hemoglobin polymer: structurefunction correlates. In: Embury SH, Hebbel RP, Mohandas $\mathrm{N}$ et al. (eds.). Sickle Cell Disease: basic principles and clinical practice. New York: Lippincott-Raven, 1994. p. 33-51.

3. Fadlon E, Vordermeier S, Person TC. Blood polymorphonuclear leukocytes from the majority of sickle cells patients in the crisis phase of the disease show enhanced adhesion to vascular endothelium and increased expression of CD64. Blood. 1998;91(1):266-74.

4. Hebbel RP, Vercellotti GM. The endothelial biology of sickle cell disease. J Lab Clin Med. 1997;129(3):288-93.

5. Hebbel RP, Moldow CF, Steinberg MH. Modulation of erythrocyteendotelial interactions and the vasocclusive severity of sickling disorders. Blood. 1981;58(5):947-52.

6. Wang CW. The patophisiology, prevention, and treatment of stroke in sickle cell disease. Curr Opin Hematol. 2007;14(3):191-7.

7. Platt OS, Thorington BD, Brambilla DJ. Pain in sickle cell disease. Rates and risk factors. N Engl J Med. 1991;325(1):11-6.

8. Serjeant GR, Ceulaer CD, Lethbridge R. The painful crisis of homozygous sickle cell disease: clinical features. Br J Haematol. 1994;87(3):586-91

9. Koshy M, Entsuah R, Koranda A. Leg ulcers in patients with sickle cell disease. Blood. 1989;74(4):1403-08.

10. Ademiluyi SA, Rotimi VO, Cocker AO. The anaerobic and aerobic bacterial flora of leg ulcers in patients with sickle-cell disease. J Infect. 1988;17(2):115-20.

11. Flock P, Gibbs L, Sykes N. Diamorphine-metronidazole gel effective for treatment of painful infected leg ulcers. J Pain Symptom Manage. 2000;20(6):396-7.

12. Krajnik M, Zylicz Z, Finlay I, Luczak J, van Sorge AA. Potencial uses of topical opioids in palliative care - report of 6 cases. Pain. 1999;80(1-2):121-5.

13. Twillman RK, Long TD, Cathers TA, Mueller DW. Treatment of painful skin ulcers with topical opioids. J Pain Symptom Manage. 1999; 17(4):288-92

14. Ballas SK. Treatment of painful sickle cell leg ulcers with topical opioids. Blood. 2002;99(3):1096.

15. Zeppetella G, Paul J, Ribeiro MD. Analgesic efficacy of morphine applied topically to painful ulcers. J Pain Symptom Manage. 2003; 25(6):555-8

16. Zeppetella G, Ribeiro MD. Morphine in intrasite gel applied topically to painful ulcers. J Pain Symptom Manage. 2005;29(2):118-9.

17. Abdelmageed R, Labyad N, Watson DG, Pournamdari M, Cable CG, Stanley E. Evaluation of the stability of morphine sulphate in combination with Instillagel. J Clin Pharm Ther. 2008;33(3):263-71.

18. Levine JD, Taiwo YO. Involvement of the mu-opiate receptor in peripheral analgesia. Neuroscience. 1989;32:571-5.

19. Samczewska G, Kolodziejska J, Cialkowska-Rysz A, PiechotaUrbanska M. The effect of cross-linking base on the properties of hydrogels with carbopol and on pharmaceutical availability of morphine sulphate. Arch Med Sci. 2007;3(1):19-26.

20. Nahata MC, Morosco RS, Hipple TF. Stability of morphine sulfate in bacteriostatic $0.9 \%$ sodium chloride injection stored in glass vials at two temperatures. Am J Hosp Pharm. 1992;49(11):2785-6.

21. Lobo CLC, Marra VN, Silva RMG. Crises dolorosas na doença falciforme. Rev. Bras. Hematol. Hemoter. 2007;29(3):247-58.

Avaliação: Editor e dois revisores externos

Conflito de interesse: sem conflito de interesse

Recebido: 06/09/2009

Aceito após modificações: 15/12/2009 